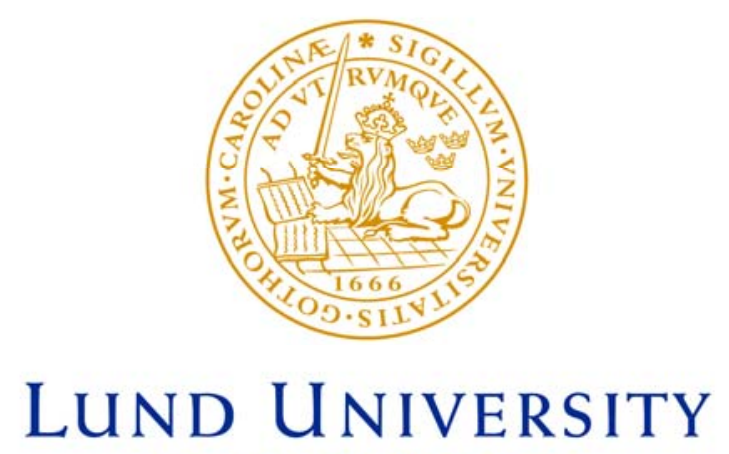

Faculty of Medicine

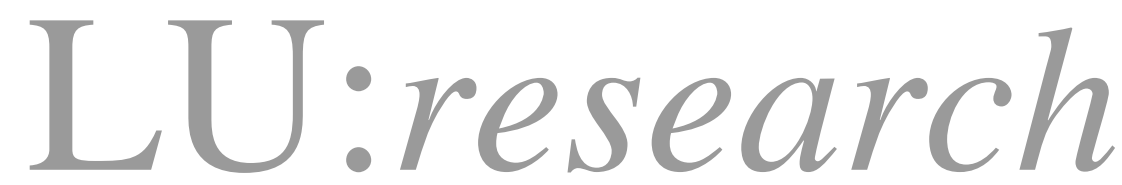

Institutional Repository of Lund University

This is an author produced version of a paper published in Acta physiologica. This paper has been peer-reviewed but does not include the final publisher proof-corrections or journal pagination.

Citation for the published paper:

Lundborg, $G$ and Rosén, B.

"Hand function after nerve repair"

Acta physiologica, 2007, Vol: 189, Issue: 2, pp. 207-17.

http://dx.doi.org/10.1111/j.1748-1716.2006.01653.x

Access to the published version may

require journal subscription.

Published with permission from: Blackwell Pub. 


\title{
Hand function after nerve repair
}

\author{
Göran Lundborg, Birgitta Rosén
}

Department of Hand Surgery, Malmö University Hospital, Lund University, Sweden

Corresponding author: Göran Lundborg, Department of Hand Surgery, Malmö University Hospital, SE-205 02 Malmö, Sweden. Tel: +46 403367 69, fax: +46 4092 88 55, e-mail: goran.lundborg@med.lu.se. 


\section{Abstract}

Treatment of injuries to major nerve trunks in the hand and upper extremity remains a major and challenging reconstructive problem. Such injuries may cause long lasting disabilities in terms of lost fine sensory and motor functions. Today there is no surgical repair technique that can ensure recovery of tactile discrimination in the hand of an adult patient following nerve repair while very young individuals usually regain a complete recovery of functional sensibility. Posttraumatic nerve regeneration is a complex biological process where the outcome depends on multiple biological and environmental factors such as survival of nerve cells, axonal regeneration rate, extent of axonal misdirection, type of injury, type of nerve, level of the lesion, age of the patient and compliance to training. A major problem is the cortical functional reorganisation of the hand representation which occurs as a result of axonal misdirection. Although protective sensibility usually can occur following nerve repair tactile discriminative functions seldom recover - a direct result of the cortical remapping. Sensory re-education programmes are routinely applied to facilitate understanding of the new sensory patterns provided by the hand. New trends in hand rehabilitation focus on modulation of central nervous processes rather than peripheral factors. In the initial phase following nerve injury and repair (phase 1) principles are being evolved to maintain the cortical hand representation by using the brain capacity for visuo-tactile and audio-tactile interaction. After reinnervation of the hand has started (phase 2), selective de-afferentiation, such as cutaneous anaesthesia of the forearm of the injured hand, allows expansion of the nerve injured cortical hand representation, thereby enhancing the effects of sensory relearning. Recent data support the view that training protocols specifically addressing the relearning process will substantially increase the possibilities for improved functional outcome after nerve repair.

Key words: Brain plasticity, cortical reorganisation, hand function, nerve regeneration, nerve repair 
Peripheral nerve lesions remain serious conditions and are one of the most challenging surgical reconstructive problems, especially in the upper extremity and hand. Nerve injuries may seriously interfere with an individual's capacity to function adequately, and the acquired disability is often dramatic: a hand without sensibility is usually a hand without function. Most frequently nerve injuries are seen in the upper extremity of young males (McAllister et al. 1996, Noble et al. 1998), there is a high probability of work loss (Jaquet et al. 2001) and the quality of life for the patient may be greatly impaired. There is often lifelong hand function impairment, pain, dysaestesia and cold intolerance. There is also a substantial economic impact of nerve injuries of the patient as well as society: the cost for an employed person in Sweden who has sustained a median nerve injury is more than 51,000 € (Rosberg et al. 2005).

Despite an enormous amount of new data and evolving new scientific concepts nerve injuries still belong to the most challenging and difficult surgical reconstructive problems. Today there is no surgical technique which can ensure recovery of tactile discrimination in the hand of an adult after a median nerve lesion. Thus, considering the impact of nerve injuries on quality of life as well as working capacity and economy there are good reasons to re-evaluate and revise some of the current principles for nerve repair.

\section{The sensational hand}

The human hand is not only a working tool but a delicate instrument of great importance for our daily activities and well-being. It's an organ that protects us by the sense of touch and one that makes our expression to the world heard via body language or via the art of painting or music. The hand has an enormous capacity to perceive, to execute and to express simultaneously, in the explorative act of touch (Gibson 1962). 
Besides the capacity for delicate motor functions the hand represents a sense organ with extremely well developed sensory functions. Besides protective sensibility the term tactile gnosis is often used to illustrate the specific aspects of functional sensibility representing the interplay between peripheral function of the nerve en the interpretation of sensory impressions in the somatosensory cortex of the brain (Moberg 1958). The discriminative touch, one aspect of tactile gnosis, is dependent on cutaneous mechanoreceptors in the hand sensitive to pressure, vibration and stretching. The physiology of function and distribution of the mechanoreceptors in the subepidermal, dermal and subcutaneous layers of the volar glabour skin of the hand have been well defined and described in numerous investigations (Johansson \& Vallbo 1983, Johansson \& Vallbo 1979, Stark et al. 1998, Vallbo \& Hagbarth 1968, Vallbo \& Johansson 1984). This is a function that enables perception and localisation of touch, discrimination of touch and recognition of qualities and identification of objects without using vision. In this view the hand can be described as a sense organ, strongly linked to the brain (Lundborg 2003, Lundborg 2004, Wynn-Parry 1986). The well developed feedback system between the hand and the brain, with continuous proprioception and tactile input that are coordinated with memory systems in the brain, is a prerequisite for regulation of grip force and grip speed (Johansson 2002). The feedback from a functioning sense of touch is also essential for the body awareness (Ramachandran \& Hirstein 1998). A nerve injury leaving the hand with impaired sensation will have a high impact on the patient's capacity to use the hand and there are not only medical disabilities but also a considerable social disability.

\section{Regeneration and repair - physiological aspects}

Restoration of motor and sensory functions in the hand after nerve repair is a complex process based on multilevel cellular, chemical and functional changes - from the fingertips to brain cortex (Lundborg 2004). Axonal outgrowth and orientation is dependent on complex 
molecular mechanisms in the microenvironment with various types of mechanisms for axonal attraction or repulsion, stimulating or inhibiting the advancement of axons.

Following transection of a nerve the reactions at cell body level is a shift in metabolism from a mode of maintenance to a mode of growth expressed in structural and functional changes of the nerve cell bodies (Aldskogius \& Arvidsson 1978, Dahlin et al. 1987, Grafstein 1975, Lieberman 1971). As a result of the axonal transection a large number of neurons die as a result of apoptosis. There may be a cellular loss of $20-50 \%$ of neurons in the dorsal root ganglia (Aldskogius \& Arvidsson 1978, Liss et al. 1996, Ygge 1989) and also motor cells may die although to a lesser extent (Li et al. 1994, Novikov et al. 1995). Several factors may have an influence on the posttraumatic neuronal loss in the dorsal root ganglia such as age, time laps from injury to repair and proximity of injury. Immediate repair of a nerve may reduce the posttraumatic cell death (Ma et al. 2003).

A major problem is the axonal misdirection which, regardless of the repair technique, always occurs at the repair site so that sensory axons grow into motor Schwann cell and vice versa (DeFelipe \& Jones 1991, Lundborg 2004, Ramon y Cajal 1928, Witzel et al. 2005). In the distal segment there is a wallerian degeneration and the Schwann cells start to proliferate and produce a number of various growth factors such as no growth factor (NGF) (Heumann 1987, Thoenen et al. 1988), ciliary neurotrophic factor (CNTF), brain derived neurotrophic factors (BDNF) and NT-3, NT-4/5 and NT-5-6 (Funakoshi et al. 1993, Lundborg 2004). Invading macrophages release interleukin-1 which triggers and increased NGF transcription and NGF receptor density in the Schwann cells (Heumann et al. 1991, Taniuchi et al. 1986). For details of the physiology of regeneration and the importance of growth factors see, for instance, $\mathrm{Fu}$ and Gordon (Fu \& Gordon 1997), Terzis et al (Terzis et al. 1997), Frostick and Kemp (Frostick \& Kemp 1998), Yin et al (Yin et al. 1998), McAllister et al (McAllister et al. 1999), 
Terenghi (Terenghi 1999), Lundborg (Lundborg 2000a, Lundborg 2004) and Dahlin (Dahlin 2004, Dahlin \& Brandt 2004).

A crucial factor is the extent of "specificity" in axonal growth. The existence of "preferential motor regeneration” under strict laboratory conditions have been stressed by Brushart and coworkers (Brushart 1988, Brushart 1990, Brushart 1993, Brushart \& Seiler 1987) implying that motor fibres preferentially innervates distal motor Schwann cell tubes in contrast to distal sensory Schwann cells. The bases for this has been suggested to be the presence of specific “recognition molecules” in motor Schwann cell tubes as opposed to sensory Schwann cell tubes (Kunemund et al. 1988). However, according to Maki and associates there is specificity in sensory regeneration but not in motor regeneration. According to Maki the outgrowth of Schwann cells in the distal nerve segment has an important role in this context. Although the issue of specificity in axonal regeneration is a crucial issue opinions vary regarding the expression of specificity in experimental regeneration models. It is not known if, or to what extent, specificity mechanisms are active in clinical situations.

\section{Regeneration after nerve repair - clinical aspects}

Repair of nerves was long regarded primarily as a technical problem and various techniques have been described to make the adaptation of nerve ends as accurate as possible. Following a nerve transection the surgeon can approximate and suture the two nerve ends by putting sutures in the outer nerve sheath (epineurium) or in deeper epineurial layers to adapt separately bundles of fascicles (Lundborg 2004). It may even by possible to suture separate fascicles individually. However, the surgeon can never address individual Schwann-cell tubes or axons. Thus, regardless how accurate the repair technique is, axonal misdirection is unavoidable and constitutes the base for cortical functional reorganisations when incorrect peripheral targets are reinnervated by regenerating axons (Witzel et al. 2005). 
The classic technique is to suture only the external epineurium (Diao \& Vannuyen 2000, Lundborg 2004, Rowshan et al. 2004, Trumble \& McCallister 2000). Although the epineural repair gives a nice appearance of the suture site there may be dysalignment of the interior fascicles. An improved orientation of fascicles is achieved by the group fascicular repair technique were individual bundles of fascicles are repaired separately (Diao \& Vannuyen 2000, Lundborg 2004, Rowshan et al. 2004). With this technique fascicular groups are carefully freed by dissection under high magnification, the epineurial tissues resected over a short distance from the cut nerve ends and the fascicular bundles are sutured individually. This technique gives an improved accuracy in fascicular orientation, but there is no evidence that this technique, in general, results in improved functional outcome as compared to the epineurial technique (Lundborg 2004).

Tubes of various types have been used for primary and secondary repair of nerves (Lundborg et al. 2004). Silicone tubes were used for primary repair of human median and ulnar nerves at wrist level by Lundborg and associates (Lundborg et al. 2004), and various types of tubes, resorbable and non-resorbable, have since been used in experimental animals and clinical praxis (Archibald et al. 1991, Archibald et al. 1995, Schlosshauer \& Lietz 2004). Tube repair a short space, about $5 \mathrm{~mm}$ in length, is deliberately left between the nerve ends inside the tube. A gap is rapidly filled with fibrin and is thereafter invaded by microvessels, fibroblast, Schwann-cells and axons (Lundborg 2004).

\section{Assessment of hand function after nerve repair}

Assessment of hand function following nerve repair is not an easy task since several tests, addressing different aspects of hand function should be conducted. For appreciation of the overall function of the hand different measures are needed to quantify the outcome in a setting of modalities, such as sensibility, motor function, pain and discomfort (Jerosch-Herold 2005, 
MacDermid 2005, Rosén 1996, Rosen \& Lundborg 2003, Szabo 2001). Historically the most commonly used scale for assessment of sensory and motor functions of the hand is the MRCscales (Medical Research Council \& committee 1954). The sensory scale is however based on subjective findings, and thus it has psychometric drawbacks. Several attempts have been made to quantify the outcome over the years. The most recent is the Model Instrument for Outcome After Nerve Repair which is a model for routine documentation and quantification of the functional outcome after nerve repair at wrist or distal forearm level including sensory and motor function as well as problems from pain and discomfort in a summarised scoringsystem (Rosén \& Lundborg 2000). Specific sensibility tests can hierarchically be divided into detection tests, discrimination tests and identification tests (Fess 1990). Detection of a single stimulus is required, such as the light pressure from a filament. Most commonly SemmesWeinstein monofilaments (SWM) or von Frey’s hair (von Frey 1922) are used. Nylon filaments of different thickness are used and the test is performed in a standardised way where the subject indicates when touch by the filament can be felt. Thereby the smallest per touch/pressure can be defined (Bell-Krotoski 2002).

Various tests for tactile discrimination have been described. A commonly used test for discriminative capacity is a two-point discrimination (2PD) test which among surgeons and therapists are commonly used to assess functional hand sensibility. The classic static-twopoint discrimination test was developed by Weber and popularised by Moberg (Moberg 1958, Moberg 1962). In this test one or two points are randomly applied to the tested skin area and the subject is asked whether one or two points are perceived. It is important that 2PD results always are accompanied by a detailed description as to how the test was performed since the amount of pressure towards the skin can influence the result considerably (Jerosch-Herold 2005, Lundborg \& Rosen 2004). 
The recently described STI-test (shape/texture-identification) is a standardised test based on active touch with identification of shapes and textures of increasing difficulty (Rosén \& Lundborg 1998).

The model instrument (Model Instrument for Outcome After Nerve Repair) mentioned earlier, based on subjective as well as objective measures, focusing on the totality, take into account sensory, motor and pain/discomfort aspects. This model correlates well the patient's opinion of the impact of the nerve injury on activities of daily living (ADL) (Rosén \& Lundborg 2000).

\section{Factors influencing the outcome}

The outcome from nerve repair is much dependent on prevailing conditions as well as the technique that is used. However, the outcome from peripheral nerve surgery varies considerably among patients, even when conditions as well as surgical techniques are virtually identical. Various factors are known to influence the outcome from nerve repair.

Age

Although the outcome from nerve repair is disappointing in adults (Allan 2000, JeroschHerold 1993, Jerosch-Herold 2000, Kallio \& Vastamäki 1993, Rosén et al. 2000) it is well known that children usually achieve superior functional results (Lundborg \& Rosen 2001). Although factors as generally shorter regeneration distance in children and that the regeneration capacity in general can be expected to be better, the better adaptability of the brain in children with a superior ability of central adaptation to the new pattern and afferent impulses presented by misdirected axons have usually been proposed as an explanation. There seems to be a critical age period for recovery of functional hand sensibility with the best results being seen in those younger than the age of 10 years, followed by rapid decline levelling out after late adolescence (Lundborg \& Rosen 2001). Interestingly, there is a striking 
analogy between this pattern and the pattern illustrating the scores of immigrants on a grammar test, plotted against the age at which they start to learn a new language (Lundborg 2004, Lundborg \& Rosen 2001).Thus, the critical period for regaining discriminative tactile capacity after nerve repair is analogous to a corresponding critical period for acquisition of a second language, indicating a strong learning component in acquisition of functional sensibility as well.

\section{Cognitive brain capacities}

Specific cognitive capacities of the brain such as verbal learning capacity and visuo-spatial logic capacity can help to explain variations in the recovery of functional sensibility in adult after nerve repair (Rosén et al. 1994). Verbal learning capacity and visuo-spatial cognitive capacity have been shown to play a significant role for recovery of functional sensibility in median an ulnar nerve repair in adults.

\section{Timing of repair}

It is generally agreed that freshly transected nerves should be repaired acutely with no or minimal delay (Birch \& Raji 1991, Diao \& Vannuyen 2000, Lundborg 2004, Trumble \& McCallister 2000). Early repair will substantially reduce the postoperative nerve cell death (Ma et al. 2003) and at this time nature landmarks such as epineurial blood vessels can still be used to ensure a correct matching of the nerve ends. With increasing preoperative delay the results become progressively worse as a result of fibrosis of the distal nerve segment, atrophy of Schwann-cells and progressive loss of neurons.

\section{Type of nerve}

The type of nerve that is injured considerably influences the outcome. If a pure motor nerve is injured the risk for mismatch between motor axons and sensory axons is eliminated thus 
optimising the accuracy in reinnervation. For pure sensory nerves, such as a digital nerve the situation is analogous.

\section{Level of injury}

After nerve transection there is an initial delay followed by sprouting and axonal outgrowth. A nerve outgrowth rate of at most 1-2 mm per day in humans have been suggested as likely (Buchthal \& Kühl 1979). In digital nerve injuries there is only a short distance separating the regenerating axons from their distal targets while injuries at upper arm level create different situations with longer time before regeneration of the hand occurs. Median nerve lesions at wrist level may require 3-4 months before the first signs of reinnervation in the hand occur.

\section{Type of injury}

A crush lesion always results in better functional outcome as compared to total severance of a nerve trunk (Lundborg 2004). The initial delay is shorter and the growth of axons proceeds as a faster rate after a crush injury as compared to a nerve transection. The Schwann-cell basal lamina are still in continuity and can thus guide the axons back to their original peripheral targets. The correct peripheral reinnervation of the crush injuries are reflected in a perfect restoration of the original cortical representational areas corresponding to the reinnervated body part (Merzenich \& Jenkins 1993).

\section{The role of the brain in nerve repair}

Clinical experience show that the outcome from nerve repair in adults is often disappointing and far from satisfactory, especially with respect to recovery of tactile discrimination (Allan 2000, Jerosch-Herold 1993, Jerosch-Herold 2000, Kallio \& Vastamäki 1993, Lundborg et al. 2004, Moberg 1991, Rosén 2000, Wynn-Parry 1986). Introduction of microsurgery and refined surgical repair techniques have not led to dramatically improved results (Lundborg 
2000b, Lundborg 2003, Lundborg 2004). Thus, there are good reasons to look for explanatory factors in the central nervous system in addition to the cellular and biochemical events which are associated with degeneration and regeneration in the peripheral nervous system. A nerve injury in the upper extremity is followed by profound functional reorganisational changes in brain cortex, mainly due to misdirection of regenerating axons. A major component in rehabilitation after nerve injury should therefore be to focus on the relearning process which is required to learn the "new language spoken by the hand".

\section{What happens in the brain after nerve injury and repair?}

A nerve injury in the hand or arm represents a sudden de-afferentiation with immediate and longstanding influence on the cortical hand representation as well as the representation of adjacent cortical territories (Chen et al. 2002, Kaas et al. 1983, Merzenich et al. 1983, Wall et al. 1986, Wall et al. 2002). After a median nerve transection there is a silent "black hole" in the somatosensory brain cortex corresponding to the median nerve projectional areas. Rapidly, adjacent cortical areas expand and occupy the former median nerve territory (Merzenich et al. 1983, Silva et al. 1996). These changes which happen within minutes are probably based on unmasking of normally occurring but inhibited synaptic connections. They will last over the initial post injury period before regenerating axons have reached the hand. During this period the hand is without sensation and there is no sensory input from median innervated areas. In the following text this period will be named phase 1.

Although our microsurgical nerve repair techniques have been refined to an optimal level there is still a great extent of misorientation of regenerating axons at the repair site. Thus, the skin areas of the hand will, to a large extent, not be reinnervated by their original axons. Instead they may be reinnervated by axons originally innervating other parts of the hand. The result is significant reorganisational changes in the cortical territory where the median nerve 
is normally represented. The originally well-organised hand representation is changed to a mosaic-like pattern (Florence et al. 1994, Jain et al. 1998, Kaas \& Florence 1997, Wall et al. 1986) and the median nerve does not recapture all of original territory. The former well defined individual cortical representation of separate fingers disappears and changes into distorted discontinuous islands. Surfaces of the skin with normally well-defined cortical representations such as the thumb, a segment of a finger, or a palmar pad, now become represented across multiple cortical patch-like areas, sometimes overlapping (Lundborg 2004, Wall et al. 1986). This knowledge is based primarily on primate experiments, but analogous findings have been made also in humans on basis of fMRI techniques (Hansson \& Brismar 2003). In the following text this period, representing beginning reinnervation of the hand, is named phase 2. After a median nerve injury at wrist level the phase 2 usually begins 3-4 months after nerve repair.

\section{Sensory re-education and sensory relearning - current concepts}

Following nerve injury and repair a relearning process is required for recovery of functional sensibility. Due to misdirection of axons and the consequence remapping of the cortical hand representation "the hand speaks a new language to the brain” (Dellon 1981, Dellon et al. 1974, Lundborg 2004, Wynn-Parry \& Salter 1976). This new language has to be interpreted by the brain, a process which can be achieved by sensory relearning through sensory reeducational programs. It is not known how such programs influence the functional cortical organisation (Florence et al. 2001). The functional improvement seen after training may be based either on normalisation of the distorted hand map or it can be due to adaptations in higher brain centres with a capacity to decipher the distorted hand map.

Learning is a key word in the rehabilitation process after all injuries. New sensory and motor codes are presented to the brain that has to cope with this for purposeful sensory-motor interaction and functional use. The extensive cortical reorganisational changes which occur 
after nerve repair requires a relearning process in order to adapt to the new and distorted afferent sensory input when familiar objects are touched - the mind does not understand the new "sensory code" associated with specific textures and shapes. To facilitate and enhance this process, specific programs for sensory re-education are routinely used in adult patients for regaining tactile gnosis, starting once touch can be perceived (Callahan 1995, Dellon 1997, Dellon 1981, Dellon et al. 1974, Rosén 2003, Wynn-Parry \& Salter 1976). According to these strategies, the brain is reprogrammed on the basis of a relearning process (Lundborg 2004). First, the perception of different touch modalities and the capacity to localise touch is trained, followed by touching and exploration of items, presenting shapes and textures of varying and increasing difficulty with the eyes open and closed. In this way an alternate sense (vision) assists the training and improves the deficient sense (sensation).

However, the sensory re-education programs that are used today were designed in the 1970s and 1980s and have not been changed much since then. They do not have a solid scientific base and are not updated in view of evolving concepts of learning mechanisms, cortical remodelling and brain plasticity. They are not taking into account the time factor in view of the rapid cortical reorganisational changes which follow a changed sensory input (Rosén 2003, Rosen \& Lundborg 2004).

\section{New strategies in sensory re-education and sensory relearning}

According to routine sensory re-education protocols the sensory training starts at first in

phase 2, that is when beginning reinnervation of the hand has started and when the cortical reorganisational changes resulting from the nerve injury are well manifested. The cortical hand representation has since long disappeared and is occupied by expanding adjacent cortical areas. In our current and evolving protocols for sensory re-education we focus on the timing 
of initiation of the training program with emphasis on new training concepts not only in phase 2 but also in phase 1, i.e. early after nerve injury and repair, long before hand reinnervation has started. The strategy is to activate the cortical area representing the damaged nerve, hereby diminishing the cortical reorganisation aiming at a maintenance of the cortical representation of the denervated body part.

\section{Phase one}

\section{Maintaining the cortical hand map}

\section{Background}

Nerve transection results in a rapid disappearance of the corresponding cortical representation. For instance, a combined median and ulnar nerve injury is followed by disappearance of the cortical hand representation followed by a rapid expansion of the adjacent cortical hand territories. In our treatment regimen in phase 1, we focus on maintaining the cortical hand representation by using the brains capacity for visuo-tactile and audio-tactile interaction. Activation of motor neurons - “mirror neurons” in premotor cortex by the mere observation of hand motor actions is a well known phenomenon which is believed to play a fundamental role in both action and understanding and imitation (Rizzolatti \& Craighero 2004, Rizzolatti et al. 2001). Activation of somatosensory cortex by visual observation of touch has been demonstrated with reference to the lower extremity (Keysers et al. 2004) and does occur also with observation of a hand being touched (Avikainen et al. 2002, Grezes et al. 2003, Hansson et al. 2005). Premotor cortex may be activated also by reading or listening to action or words (Hauk et al. 2004). It is well known that the brain has a multimodal capacity meaning that specific neurons and association cortical areas respond to stimuli provided by touch as well as vision and hearing (Bavelier \& Neville 2002). In analogy, an interesting principle is activation of somatosensory cortex by listening to the 
friction sound of a hand being touched or a hand touching various textures (Lundborg \& Rosen 2003, Lundborg et al. 2005).

\section{Training concepts (phase one)}

- Visuo-tactile interaction and mirror training

The patient's observation of his hand being touched by the therapist is an important component of early sensory training which might activate the cortical hand area due to visuo-tactile interaction. The effect can be further enhanced by using mirror training. We use a mirror placed transversally in front of the patient with the nerve injured hand hidden behind the mirror, the healthy hand being reflected in the position of the injured hand (Ramachandran et al. 1995, Ramachandran \& Hirstein 1998). Touching the healthy hand gives and illusion of touching the nerve-injured hand. In these training sessions the patient often gets a perception of the tactile stimuli in the nerveinjured non-sensate hand by the combined mirror illusion and the true touch of the healthy hand.

- Audio-tactile interaction and the use of Sensor Glove

We use a Sensor Glove System with microphones mounted dorsally at fingertip levels in a glove connected to earphones - via a miniature stereo processor. With this system "the patients can listen to what the hand feels". Thus, auditory stimuli substitute for absent tactile stimuli - specific and typical friction sounds are associated with touching of various textures.

In a clinical randomised prospective study run at five hand centres in Sweden patients with median nerve injuries were randomised either to a group using the Sensor Glove from the first postoperative day or a group not using the glove but subjected to routine sensory re-educational programs. Preliminary results, obtained from one year followup shows that tactile discrimination, as assessed in the STI-test and hand dexterity, 
assessed by the Sollerman-test showed a significantly better recovery in the group using the Sensor Glove (Lundborg \& Rosen 2003, Rosen \& Lundborg 2003).

\section{Phase two}

\section{Enhancing the effects of sensory re-education}

\section{Background}

The brain's capacity for rapid redistribution of cortical resources as a component of brain plasticity has been well described in the literature in rehabilitation of stroke patients. For instance, it has been shown that selective anaesthesia of ventral roots of C5-C8 (motor innervation of shoulder and elbow) results in enhanced motor function of the hand (innervation C8-C11 (Muellbacher et al. 2002)). The mechanism is that de-afferentiation of specific cortical area (shoulder and elbow representations) allows expansion of adjacent cortical representational areas (the hand). In analogy cutaneous de-afferentiation of the forearm would hypothetically result in expansion of the adjacent cortical hand representation.

\section{Training concepts (phase two)}

\section{Cutaneous de-afferentation of the forearm}

- In our treatment regime we perform anaesthesia of the forearm proximally to the nerve injured hand with the purpose of allowing expansion of the cortical hand representation. Cutaneous anaesthesia of the volar part of the forearm is induced by EMLA-crème twice a week for two weeks. This is combined with intense classic sensory training. In a double blind, randomised clinical study on patients treated for median or ulnar nerve injuries the EMLA-group showed a significantly improved tactile discrimination as compared to the control group (Rosén et al. 2005), subjected to sensory training only, when assessed at two and four weeks after the last EMLAtreatment. 


\section{Functional outcome after nerve repair}

Following nerve repair at distal forearm level of major nerve trunks the fingers may be without sensibility for up to six months before reinnervation at finger level occurs. Using the diagnos specific outcome instrument Model Instrument for Outcome after Nerve Repair) (Rosén \& Lundborg 2001), a reference interval for the outcome with the estimated 95\% predicted values for the outcome show ongoing improvements up to five years after the nerve repair.

In spite of the use of microsurgical techniques for nerve repair median, ulnar or combined injuries lead to long lasting disabilities in terms of lost fine sensory and motor functions, and in addition pain and discomfort from hyperaesthesia and cold intolerance that can be very problematic with large impact on activities of daily living (ADL) (Carlsson et al. 2003, Jaquet et al. 2001, Rosén 1996). The individuals' ability to experience and interact with the surrounding world is hereby disturbed.

Five years following surgery a mean Functional Symptom Score of 19 ( $0=$ no disability, 100=max disability) on the DASH (Disability of the Arm Shoulder and Hand) questionnaire has been reported (Jaquet 2004). In a recent Dutch study 59\% of patients with median or ulnar nerve repairs returned to work within one year with an average time off work of 31 weeks (Jaquet 2004). Substantial costs for the society are also generated in terms of sick leave. A mean cost of 51000 Euro for a median nerve repair has been calculated (Rosberg et al. 2005).

In addition to the large number of peripheral and central factors including active and conscious use of the hand in activities of daily life, combined with high motivation by the patient, is since long reported to be a factor of great importance for useful return of functional sensibility (Callahan 1995). Bruyns et al found that high education, high compliance to hand therapy and an isolated injury predict quicker return to work in patients with median and/or 
ulnar nerve injuries (Bruyns et al. 2003). A recent meta-analysis showed that age, site, injured nerve and delay significantly influence the prognosis after nerve repair (Ruijs et al. 2005).

The surgeon's ambition is to use repair techniques, which brings a maximal number of nerve fibres into peripheral cutaneous territories. There are however at least three strong indications that central nervous factors associated with cortical re-modelling represent a major reason for the inferior functional outcome following nerve repair: 1) children up to the age of 10-12 usually present excellent recovery of functional sensibility in contrast to adult patients. This critical "age-window" for perfect sensory recovery presented by children corresponds well to what is known from other types of learning processes, for instance the ability for acquisition of a second language (Lundborg \& Rosen 2001); 2) cognitive functions are important explanatory factors in adults for variations in recovery of tactile discrimination (Jaquet 2004, Rosén et al. 1994); 3) The peripheral repair technique in median nerve lesions has not been found to influence the functional outcome in a clinical randomised study at a five year followup (Lundborg et al. 2004). Silicone tubular repair, leaving a short distance between the nerve cuts, was compared with the outcome from routine microsurgical repair in a clinical randomised prospective study, comprising 30 patients with median or ulnar nerve injuries in the distal forearm. Postoperatively, the patients were assessed regularly over a 5-year period with neurophysiological and clinical assessments. After 5 years there was no significant difference in outcome between the two techniques except that cold intolerance was significantly less severe with the tubular technique. The most significant improvement of perception of touch occurred during the first postoperative year, while improvement of motor function could be observed much later (Rosén et al. 2000). In the total group there was however an ongoing improvement of functional sensibility throughout the 5 years after repair although there was no further impairment in nerve conduction velocity or amplitude after the two first years (Lundborg et al. 2004). This supports that the central nervous factors 
associated with the cortical remodelling after a nerve repair are important, and that efforts to improve the results from nerve repair in the future must address the brain as well as the peripheral nerve.

\section{References}

Aldskogius, H. \& Arvidsson, J. 1978. Nerve cell degeneration and death in tregeminal ganglion of the adult rat following peripheral nerve transection. $J$ Neurocytol 7, 229250.

Allan, C.H. 2000. Functional results of primary nerve repair. Hand Clin 16, 67-72.

Archibald, S.J., Krarup, C., Shefner, J., Li, S.T. \& Madison, R.D. 1991. A collagen-based nerve guide conduit for peripheral nerve repair: an electrophysiological study in rodents and non-human primates. J Comp Neurol 306, 685-696.

Archibald, S.J., Shefner, J., Krarup, C. \& Madison, R.D. 1995. Monkey median nerve repaired by nerve graft or collagen nerve guide tube. J Neurosci 15, 4109-4123.

Avikainen, S., Forss, N. \& Hari, R. 2002. Modulated activation of the human SI and SII cortices during observation of hand actions. Neuroimage 15, 640-646.

Bavelier, D. \& Neville, H.J. 2002. Cross-modal plasticity: where and how? Nat Rev Neurosci 3, 443-452.

Bell-Krotoski, J. 2002 Sensibility testing with the Semmes-Weinstein monofilament. In:(Ed, Mackin, C., Skirven, Schneider, Osterman, Mosby) Rehab of the hand and upper extremity, Fifth edition pp. 194-213. S:t Louis.

Birch, R. \& Raji, A. 1991. Repair of median and ulnar nerves - primary suture is best. $J$ Bone Joint Surg 73B, 154-157.

Brushart, T.M.E. 1988. Preferential reinnervation of motor nerves by regenerating motor axons. J Neurosci 8, 1026-1031.

Brushart, T.M.E. 1990. Preferential motor reinnervation: a sequential double-labeling study. Restor. Neurol. Neurosci. 1, 281-287.

Brushart, T.M.E. 1993. Motor axons preferentially reinnervate motor pathways. The Journal of Neuroscience 13, 2730-2738.

Brushart, T.M.E. \& Seiler, W.A. 1987. Selective reinnervation of distal motor stumps by peripheral motor axons. Exp. Neurol. 97, 289-300.

Bruyns, C.N., Jaquet, J.B., Schreuders, T.A., Kalmijn, S., Kuypers, P.D. \& Hovius, S.E. 2003. Predictors for return to work in patients with median and ulnar nerve injuries. $J$ Hand Surg $[\mathrm{Am}]$ 28, 28-34.

Buchthal, F. \& Kühl, V. 1979. Nerve conduction, tactile sensibility, and the electromyogram after suture or compression of peripheral nerve: a longitudinal study in man. J. Neurol. Neurosurg. Psych. 42, 436-451.

Callahan, A.D. 1995 Methods of compensation and reeducation for sensory dysfunction. (Eds, Hunter, J.M., Mackin, E.J. and Callahan, A.D.) Rehabilitation of the hand pp. 701714. C.V. Mosby, St Louis.

Carlsson, I., Cederlund, R., Holmberg, J. \& Lundborg, G. 2003. Behavioural treatment of post-traumatic and vibration-induced digital cold sensitivity. Scand J Plast Reconstr Surg Hand Surg 37, 371-378.

Chen, R., Cohen, L.G. \& Hallett, M. 2002. Nervous system reorganization following injury. Neuroscience 111, 761-773. 
Dahlin, L.B. 2004. The biology of nerve injury and repair. J Am Soc Surg Hand 4, 143-155.

Dahlin, L.B. \& Brandt, J. 2004. Basic science of peripheral nerve repair - Wallerian degeneration/growth cone. Oper Tech Orthop 14, 138-145.

Dahlin, L.B., Nordborg, C. \& Lundborg, G. 1987. Morphological changes in nerve cell bodies induced by experimental graded nerve compression. Exp Neurol 95, 611-621.

DeFelipe, J. \& Jones, E.G. 1991 Cajal's degeneration \& regeneration of the nervous system, ed. Oxford University Press, New York.

Dellon, A. 1997 Somatosensory testing and rehabilitation, ed. The American Occupational Therapy Association, Inc. Bethseda.

Dellon, A.L. 1981 Sensibility and re-education of sensation in the hand, ed. Williams \& Wilkins, Baltimore.

Dellon, A.L., Curtis, R.M. \& Edgerton, M.T. 1974. Reeducation of sensation in the hand after nerve injury and repair. Plastic\&Reconstructive Surgery 53, 297-305.

Diao, E. \& Vannuyen, T. 2000. Techniques for primary nerve repair. Hand Clin 16, 53-66, viii.

Fess, E. 1990 Documentation: essential elements of an upper extremity assessment battery.. In:(Ed, al, H.e.) Rehabilitation of the hand.Mosby Company, St Louis.

Florence, S.L., Boydston, L.A., Hackett, T.A., Lachoff, H.T., Strata, F. \& Niblock, M.M. 2001. Sensory enrichment after peripheral nerve injury restores cortical, not thalamic, receptive field organization. Eur J Neurosci 13, 1755-1766.

Florence, S.L., Garraghty, P.E., Wall, J.T. \& Kaas, J.H. 1994. Sensory afferent projections and area 3b somatotopy following median nerve cut and repair in macaque monkeys. Cerebral cortex 4, 391-407.

Frostick, S.P. \& Kemp, G.J. 1998. Schwann cells, neurotrophic factors, and peripheral nerve regeneration. Microsurgery 18, 397-405.

Fu, S.Y. \& Gordon, T. 1997. The cellular and molecular basis of peripheral nerve regeneration. Molecular Neurobiology 14, 67-116.

Funakoshi, H., Frisen, J., Barbany, G. et al. 1993. Differential expression of mRNAs for neurotrophins and their receptors after axotomy of the sciatic nerve. J Cell Biol 123, 455-465.

Gibson, J.J. 1962. Observations on active touch. Psychol review 69, 477-491.

Grafstein, B. 1975. The nerve cell body response to axotomy. Exp Neurol 48, 32-51.

Grezes, J., Armony, J.L., Rowe, J. \& Passingham, R.E. 2003. Activations related to "mirror" and "canonical" neurones in the human brain: an fMRI study. Neuroimage 18, 928937.

Hansson, T., Björkman, A., Nylander, L., Nyman, T., Rosén, B. \& Lundborg, G. (2005) In Xth FESSH CongressGöteborg 15-18 June.

Hansson, T. \& Brismar, T. 2003. Loss of sensory discrimination after median nerve injury and activation in the primary somatosensory cortex on functional magnetic resonance imaging. J Neurosurg 99, 100-105.

Hauk, O., Johnsrude, I. \& Pulvermuller, F. 2004. Somatotopic representation of action words in human motor and premotor cortex. Neuron 41, 301-307.

Heumann, R. 1987. Regulation of the synthesis of nerve growth factor. J Exp Biol 132, 133150.

Heumann, R., Hengerer, B., Brown, M. \& Perry, H. 1991. Molecular mechanisms leading to lesion-induced increases in nerve growth factor synthesis. Ann N Y Acad Sci 633, 581582.

Jain, N., Florence, S.L. \& Kaas, J.H. 1998. Reorganization of somatosensory cortex after nerve and spinal cord injury. News Phsysiol Science 13, 143-.

Jaquet, J. (2004) In Department of Plastic and Reconstructive SurgeryErasmus Medical Center, Erasmus University, Rotterdam. 
Jaquet, J.B., Luijsterburg, A.J., Kalmijn, S., Kuypers, P.D., Hofman, A. \& Hovius, S.E. 2001. Median, ulnar, and combined median-ulnar nerve injuries: functional outcome and return to productivity. J Trauma 51, 687-692.

Jerosch-Herold, C. 1993. Measuring outcome in median nerve injuries. Journal of Hand Surgery 18B, 624-628.

Jerosch-Herold, C. 2000. Should sensory function after median nerve injury and repair be quantified using two-point discrimination as the critical measure? Scandinavian Journal of Plastic Reconstructive Surgery and Hand Surgery 34, 339-343.

Jerosch-Herold, C. 2005. Assessment of sensibility after nerve injury and repair: a systematic review of evidence for validity, reliability and responsiveness of tests. $J$ Hand Surg [Br] 30, 252-264.

Johansson, R. \& Vallbo, Å. 1983. Tactile sensory coding in the glabrous skin of the human hand. Trands in Neurosceinces 6, 27-32.

Johansson, R.S. 2002. Dynamic use of tactile afferent signals in control of dexterous manipulation. Adv Exp Med Biol 508, 397-410.

Johansson, R.S. \& Vallbo, A.B. 1979. Tactile sensibility in the human hand: relative and absolute densities of four types of mechanoreceptive units in glabrous skin. $J$ Physiol 286, 283-300.

Kaas, J.H. \& Florence, S.L. 1997. Mechanisms of reorganization in sensory systems of primates after peripheral nerve injury. Adv Neurol 73, 147-158.

Kaas, J.H., Merzenich, M.M. \& Killackey, H.P. 1983. The reorganization of somatosensory cortex following peripheral nerve damage in adult and developing mammals. Annu Rev Neurosci 6, 325-356.

Kallio, P.K. \& Vastamäki, M. 1993. An analysis of the results of late reconstruction of 132 median nerves. Journal of Hand Surgery 18B, 97-105.

Keysers, C., Wicker, B., Gazzola, V., Anton, J.L., Fogassi, L. \& Gallese, V. 2004. A touching sight: SII/PV activation during the observation and experience of touch. Neuron 42, 335-346.

Kunemund, V., Jungalwala, F.B., Fischer, G., Chou, D.K., Keilhauer, G. \& Schachner, M. 1988. The L2/HNK-1 carbohydrate of neural cell adhesion molecules is involved in cell interactions. J Cell Biol 106, 213-223.

Li, L., Oppenheim, R.W., Lei, M. \& Houenou, L.J. 1994. Neurotrophic agents prevent motoneuron death following sciatic nerve section in the neonatal mouse. $J$ Neurobiol 25, 759-766.

Lieberman, A. 1971. The axon reaction: a review of the principal features of perikaryal response to axonal injury. Int Rev Neurobiol 14, 99-124.

Liss, A.G., af Ekenstam, F.W. \& Wiberg, M. 1996. Loss of neurons in the dorsal root ganglia after transection of a sensory peripheral nerve. An anatomical study in monkeys. Scand J Plast Reconstr Hand Surg 30, 1-6.

Lundborg, G. 2000a. A 25-year perspective of peripheral nerve surgery: Evolving neuroscientific concepts and clinical significance. J Hand Surg 25A, 391-414.

Lundborg, G. 2000b. Brain plasticity and hand surgery: an overview. J Hand Surg [Br] 25, 242-252.

Lundborg, G. 2003. Richard P. Bunge memorial lecture. Nerve injury and repair--a challenge to the plastic brain. J Peripher Nerv Syst 8, 209-226.

Lundborg, G. 2004 Nerve injury and repair. Regeneration, reconstruction and cortical remodelling, 2nd ed. Elsevier, Philadelphia.

Lundborg, G. \& Rosen, B. 2001. Sensory relearning after nerve repair. Lancet 358, 809-810.

Lundborg, G. \& Rosen, B. 2003. Enhanced sensory recovery after median nerve repair: Effects of early postoperative artificial sensibility using the sensor glove system. $J$ Hand Surg [Am] 28 Suppl 1, 38-39. 
Lundborg, G. \& Rosen, B. 2004. The two-point discrimination test--time for a re-appraisal? J Hand Surg $[\mathrm{Br}]$ 29, 418-422.

Lundborg, G., Rosén, B., Björkman, A., Nylander, L., Nyman, T. \& Hansson, T. (2005) In Xth FESSH CongressGöteborg 15-18 June.

Lundborg, G., Rosen, B., Dahlin, L., Holmberg, J. \& Rosen, I. 2004. Tubular repair of the median or ulnar nerve in the human forearm: a 5-year follow-up. J Hand Surg [Br] 29, 100-107.

Ma, J., Novikov, L.N., Kellerth, J.O. \& Wiberg, M. 2003. Early nerve repair after injury to the postganglionic plexus: an experimental study of sensory and motor neuronal survival in adult rats. Scand J Plast Reconstr Surg Hand Surg 37, 1-9.

MacDermid, J.C. 2005. Measurement of health outcomes following tendon and nerve repair. $J$ Hand Ther 18, 297-312.

McAllister, A.K., Katz, L.C. \& Lo, D.C. 1999. Neurotrophins and synaptic plasticity. Annu Rev Neurosci 22, 295-318.

McAllister, R.M., Gilbert, S.E., Calder, J.S. \& Smith, P.J. 1996. The epidemiology and management of upper limb peripheral nerve injuries in modern practice. $J$ Hand Surg [Br] 21, 4-13.

Medical Research Council \& committee, T.n.i. 1954 Results of nerve suture. In:(Ed, Seddon, H.J.) Peripheral nerve injuriesHer majesty’s Stationery Office, London.

Merzenich, M.M. \& Jenkins, W.M. 1993. Reorganization of cortical representations of the hand following alterations of skin inputs induced by nerve injury, skin island transfers, and experience. $J$ Hand Ther 6, 89-104.

Merzenich, M.M., Kaas, J.H., Wall, R.J., Nelson, M., Sur, D. \& Felleman, D. 1983. Topographic reorganization of somatosensory cortical areas $3 \mathrm{~B}$ and 1 in adult monkeys following restricted desfferentiation. Neuroscience 8, 33-55.

Moberg, E. 1958. Objective methods for determining the functional value of sensibility in the hand. Journal of Bone and Joint Surgery 40B, 454-476.

Moberg, E. 1962. Criticism and study of methods for examining sensibility in the hand. Neurology 12, 8-19.

Moberg, E. 1991. The unsolved problem - how to test the functional value of hand sensibility. Journal of Hand Therapy 4, 105-110.

Muellbacher, W., Richards, C., Ziemann, U. et al. 2002. Improving hand function in chronic stroke. Arch Neurol 59, 1278-1282.

Noble, J., Munro, C.A., Prasad, V.S. \& Midha, R. 1998. Analysis of upper and lower extremity peripheral nerve injuries in a population of patients with multiple injuries. $J$ Trauma 45, 116-122.

Novikov, L., Novikova, L. \& Kellerth, J.O. 1995. Brain-derived neurotrophic factor promotes survival and blocks nitric oxide synthase expression in adult rat spinal motoneurons after ventral root avulsion. Neurosci Lett 200, 45-48.

Ramachandran, V., Rogers-Ramachandran, D. \& Cobb, S. 1995. Touching the phantom limb. Nature 377, 489-490.

Ramachandran, V.S. \& Hirstein, W. 1998. The perception of phantom limbs, The D.O. Hebb lecture. Brain 121, 1603-1630.

Ramon y Cajal, S.R. 1928 Degeneration and Regeneration of the Nervous System, ed. Oxford University Press, London.

Rizzolatti, G. \& Craighero, L. 2004. The mirror-neuron system. Annu Rev Neurosci 27, 169192.

Rizzolatti, G., Fogassi, L. \& Gallese, V. 2001. Neurophysiological mechanisms underlying the understanding and imitation of action. Nat Rev Neurosci 2, 661-670.

Rosberg, H.E., Carlsson, K.S., Hojgard, S., Lindgren, B., Lundborg, G. \& Dahlin, L.B. 2005. Injury to the human median and ulnar nerves in the forearm--analysis of costs for 
treatment and rehabilitation of 69 patients in southern Sweden. $J$ Hand Surg [Br] 30, 35-39.

Rosén, B. 1996. Recovery of sensory and motor function after nerve repair: A rationale for evaluation. $J$ Hand Therapy 9, 315-327.

Rosén, B. (2000) Thesis - Lund University, pp. ISBN 91-628-4368-4360.

Rosén, B., Balkenius, C., Lundborg, G. 2003. Sensory re-education today and tomorrow. Review of evolving concepts. Br J Hand Ther 8, 48-56.

Rosén, B., Björkman, A. \& Lundborg, G. 2005. Improved sensory relearning after nerve repair induced by selective temporary anaesthesia - a new concept in hand rehabilitation. Scand J Plast Rec Surg Hand Surg, Submitted.

Rosén, B., Dahlin, L. \& Lundborg, G. 2000. Assessment of functional outcome after nerve repair in a longitudinal cohort. Scand J Plast Reconstr Surg Hand Surg 34, 71-78.

Rosen, B. \& Lundborg, G. 2003. A new model instrument for outcome after nerve repair. Hand Clin 19, 463-470.

Rosen, B. \& Lundborg, G. 2004. Sensory re-education after nerve repair: aspects of timing. Handchir Mikrochir Plast Chir 36, 8-12.

Rosén, B. \& Lundborg, G. 1998. A new tactile gnosis instrument in sensibility testing. Journal of Hand Therapy 11, 251-257.

Rosén, B. \& Lundborg, G. 2000. A model instrument for the documentation of outcome after nerve repair. $J$ Hand Surg 25A, 535-544.

Rosén, B. \& Lundborg, G. 2001. The long-term recovery curve in adults after median or ulnar nerve repair: a reference interval. J Hand Surg 26B, 196-200.

Rosén, B., Lundborg, G., Dahlin, L.B., Holmberg, J. \& Karlsson, B. 1994. Nerve repair: Correlation of restitution of functional sensibility with specific cognitive capacities. $J$ Hand Surg 19B, 452-458.

Rowshan, K., Jones, N. \& Gupta, R. 2004. Current surgical techniques of peripheral nerve repair. Oper Tech Orthop 14, 163-170.

Ruijs, A.C., Jaquet, J.B., Kalmijn, S., Giele, H. \& Hovius, S.E. 2005. Median and ulnar nerve injuries: a meta-analysis of predictors of motor and sensory recovery after modern microsurgical nerve repair. Plast Reconstr Surg 116, 484-494; discussion 495-486.

Schlosshauer, B. \& Lietz, M. 2004 Nerve guides. In:(Ed, al Me) Encyclopedia of Biomaterials and Biomedical Engineering pp. I1043-1055. Marcel Dekker Inc, New York.

Silva, A.C., Rasey, S.K., Wu, X. \& Wall, J.T. 1996. Initial cortical reactions to injury of the median and radial nerves to the hands of adult primates. J Comp Neurol 366, 700-716.

Stark, B., Carlstedt, T., Hallin, G. \& Risling, M. 1998. Distribution of human Pacinian coupuscles in the hand. $J$ Hand Surg 23B, 370-372.

Szabo, R.M. 2001. Outcome assessment in hand surgery: When are they meaningful. Journal of Hand Surgery 26A, 993-1002.

Taniuchi, M., Clark, H.B. \& Johnson, J.E.M. 1986. Induction of nerve growth factor receptor in Schwann cells after axotomy. Proc. Natl. Acad. Sci. USA 83, 4094-4098.

Terenghi, G. 1999. Peripheral nerve regeneration and neurotrophic factors. J Anat 194, 1-14.

Terzis, J., Sun, D. \& Thanos, P. 1997. Historical and basic science review: past, present and future of nerve repair. J Reconstr Microsurg 13, 215-225.

Thoenen, H., Bandtlow, C., Heumann, R., Lindholm, D., Meyer, M. \& Rohrer, H. 1988. Nerve growth factor: Cellular localization and regulation of synthesis. Cell Mol Neurobiol 8, 35-40.

Trumble, T.E. \& McCallister, W.V. 2000. Repair of peripheral nerve defects in the upper extremity. Hand Clin 16, 37-52.

Wall, J.T., Kaas, J.H., Sur, M., Nelson, R.J., Fellman, D.J. \& Merzenich, M.M. 1986. Functional reorganization in somatosensory cortical areas $3 \mathrm{~b}$ and 1 of adult monkeys 
after median nerve repair: Possible relationships to sensory recovery in humans. The $J$ Neuroscience 6, 218-233.

Wall, J.T., Xu, J. \& Wang, X. 2002. Human brain plasticity: an emerging view of the multiple substrates and mechanisms that cause cortical changes and related sensory dysfunctions after injuries of sensory inputs from the body. Brain Res Brain Res Rev 39, 181-215.

Vallbo, A.B. \& Hagbarth, K.E. 1968. Activity from skin mechanoreceptors recorded percutaneously in awake human subjects. Exp Neurol 21, 270-289.

Vallbo, A.B. \& Johansson, R.S. 1984. Properties of cutaneous mechanoreceptors in the human hand related to touch sensation. Human Neurobiol 3, 3-14.

Witzel, C., Rohde, C. \& Brushart, T.M. 2005. Pathway sampling by regenerating peripheral axons. J Comp Neurol 485, 183-190.

von Frey, M. 1922. Verspätete schmerzempfindungen. Zeitschrift für die gesamte Neurologie und Psychiatrie 79, 324-333.

Wynn-Parry, C.B. 1986. Peripheral nerve injuries: sensation. J Bone Joint Surg 68B, 15-19.

Wynn-Parry, C.B. \& Salter, M. 1976. Sensory re-education after median nerve lesions. The Hand 8, 250-257.

Ygge, J. 1989. Neuronal loss in lumbar dorsal root ganglia after proximal compared to distal sciatic nerve resection: a quantitative study in the rat. Brain Res 478, 193-195.

Yin, Q., Kemp, G.J. \& Frostick, S.P. 1998. Neurotrophins, neurons and peripheral nerve regeneration. J Hand Surg 23B, 433-437. 